Sir,

\section{Congenital absence of the inferior rectus muscle in a patient with neurofibromatosis}

Congenital absence of extraocular muscle is a rare cause of strabismus. Involvement of the superior oblique tendon is the most frequently reported, ${ }^{1,2}$ although rectus muscle involvement also occurs. ${ }^{3-6}$ Recently, a case of congenital absence of the superior oblique tendon was reported in a patient with neurofibromatosis type 1 (NF $1){ }^{7}$ We report a case of congenital absence of the inferior rectus muscle, also in a patient with NF 1 . Congenital absence of extraocular muscle(s) has not been a previously recognised association of this condition.

\section{Case report}

A 12-year-old white female with a history of NF 1 was referred to our unit with a complaint of being teased at school due to a cosmetically poor vertical squint. Her diagnosis of neurofibromatosis was based on a family history of the condition, along with multiple café-au-lait spots, axillary freckles, a cutaneous neurofibroma and learning difficulties. She had had a left hypertropia since birth and had been treated for amblyopia with occlusion therapy, without spectacle correction and without success. There was no history of previous eye surgery and she was otherwise well and receiving no medications.

On examination, her unaided visual acuity was $6 / 9$ N5 in the right eye and 6/60 N16 in the left eye with no pinhole improvement. She had no evidence of binocular vision and demonstrated manifest latent horizontal nystagmus in her left eye. The left hypertropia measured 20 prism dioptres in the primary position (Fig. 1), decreasing in right gaze and increasing to 35 prism dioptres in left gaze. She also had left lower lid retraction. Versions demonstrated marked underaction of the left inferior rectus (Fig. 2) and surgery was planned to resect the left inferior rectus without dissection of the lower lid retractors.

At the time of surgery, forced duction testing revealed no restrictions and there was no evidence of previous surgery. An inferior conjunctival incision was made, but the inferior rectus muscle was not identified. The conjunctival incision was extended to expose the inferior half of the globe. The inferior oblique muscle was identified and followed but still the inferior rectus muscle could not be found. It was therefore concluded to be absent. Normal superior, medial and lateral rectus

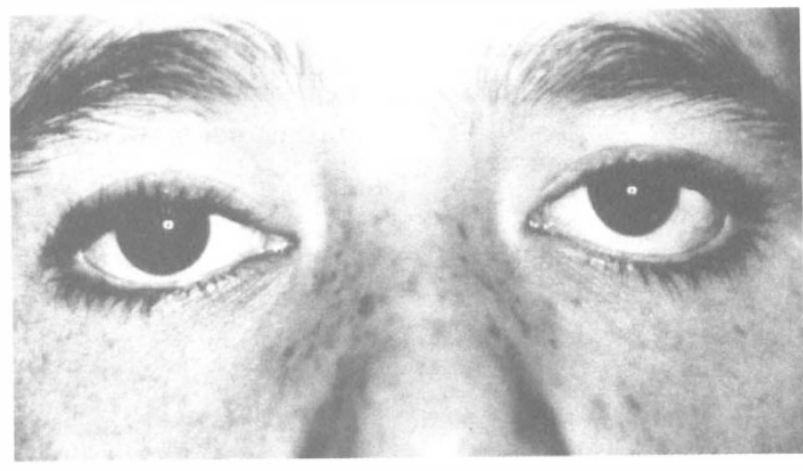

Fig. 1. Photograph with gaze in the primary position showing a left hypertropia and lower lid retraction.

muscles were identified, including normal ciliary vessels arising from the muscles. The superior oblique muscle was also normal. After due consideration of the risk of anterior segment ischaemia, a $7 \mathrm{~mm}$ recession of the left superior rectus muscle was performed.

Post-operatively, there was increased depression of the left eye with no deviation in the primary position and a good cosmetic result. A computed tomography scan of the orbits revealed no bony defects.

\section{Comment}

Congenital absence of one or more extraocular muscles is a rare entity. There is a known association with the syndromes of premature cranial bone stenosis (e.g. craniofacial dysostosis), ${ }^{8}$ thus linking cranial bone abnormalities with absent extraocular muscle. Abnormality of the orbital bones is also recognised in NF $1,{ }^{9}$ and most frequently consists of hypoplasia of the greater and lesser wings of the sphenoid bone, resulting in pulsating exophthalmos due to encephalocele.

The finding of congenital absence of the inferior rectus muscle and NF 1 in our patient may be a coincidence. However, this is the second report of absent extraocular muscle in a patient with NF 1 . Although the mechanism is unclear and may differ between conditions, a link between cranial bone abnormalities and abnormal extraocular muscle exists and may account for the findings in our patient.

In 1971, Cooper and Greenspan ${ }^{3}$ reviewed all 7 previously reported cases and presented a further case of congenitally absent inferior rectus muscle. No cases had

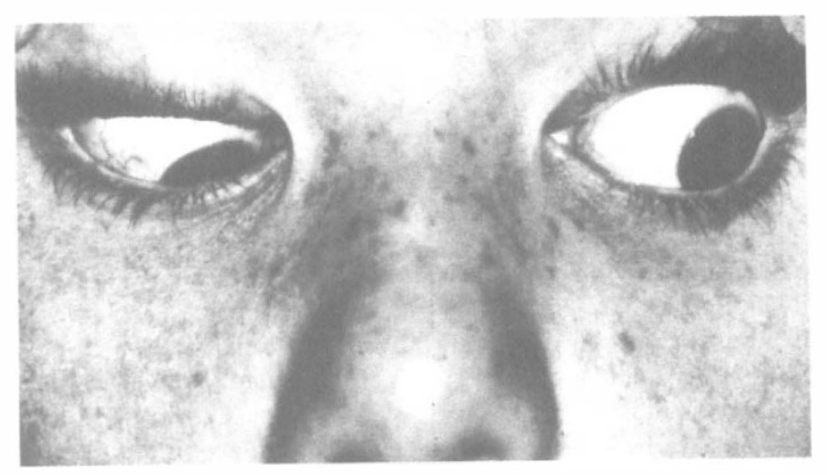

Fig. 2. Photograph with gaze in laevodepression showing marked underaction of the left inferior rectus. 
association with neurofibromatosis. Surgical correction involved a combination of superior rectus weakening with inferior oblique weakening and medial and lateral rectus tendon splitting procedures, as described by Hummelsheim. ${ }^{10}$ All cases reported success. Cooper and Greenspan $^{3}$ were the first to use full horizontal rectus tendon transposition inferiorly for this indication, as decribed by Knapp, ${ }^{11}$ with good outcome. Similar success was more recently reported by Taylor et al. ${ }^{12}$ and Munoz. ${ }^{13}$ Isolated superior rectus recession has been advocated by Vesly ${ }^{14}$ in 1965 and by Ingham et al. ${ }^{4}$ in 1986.

In a review of 21 patients, over 16 years, with isolated inferior rectus paralysis, without mechanical restriction of the globe, von Noorden and Hansell ${ }^{15}$ found that 11 were of congenital origin. No patients were reported to have neurofibromatosis. Anomalous head posture or a disfiguring hypertropia were common presenting symptoms and surgery consisted of resection of the paralysed muscle, combined with or without recession of its antagonist and/or recession of the contralateral superior oblique.

We used isolated superior rectus recession to treat our patient, with good results. To our knowledge this is the first report of a patient associating neurofibromatosis with an absent rectus muscle, and the second linking the condition with absent extraocular muscle. We would be interested to hear of other similar cases and the surgical approach to management.

\section{References}

1. Helveston EM, Giangiacomo JG, Ellis FD. Congenital absence of the superior oblique tendon. Trans Am Ophthalmol Soc 1981;79:123-33.

2. Congenital absence of the superior oblique tendon in craniofacial dysostosis. Ophthalmic Surg 1985;16:375-7.

3. Cooper EL, Greenspan JA. Congenital absence of the inferior rectus muscle. Arch Ophthalmol 1971;86:451-4.

4. Ingham PN, McGovern ST, Crompton JL. Congenital absence of the inferior rectus muscle. Aust N Z J Ophthalmol 1986;14:355-8.

5. Lin PY, Yen MY. Congenital absence of bilateral inferior rectus muscles: a case report. J Pediatr Ophthalmol Strabismus 1997;34:382-4.

6. Mather TR, Saunders RA. Congenital absence of the superior rectus muscle: a case report. J Pediatr Ophthalmol Strabismus 1987;24:291-5.

7. Newman RM, Cogen MS. Congenital absence of the superior oblique tendon in a patient with neurofibromatosis. J Pediatr Ophthalmol Strabismus 1997;34:192-4.

8. Diamond GR, Katowitz JA, Whitaker LA. Variations in extraocular muscle number and structure in craniofacial dysostosis. Am J Ophthalmol 1980;90:416-8.

9. Kaiser-Kupfer MI. Ophthalmic manifestations. In: Mulvihill $\mathrm{JJ}$, moderator. Neurofibromatosis 1 (Recklinghausen disease) and neurofibromatosis 2 (bilateral acoustic neurofibromatosis): an update. Ann Intern Med 1990;113:39-52.

10. Hummelsheim E. Weitere Erfahrungen mit partieller Sehnuberpflanzung an dem Augenmuskulen. Arch Augenheilkd 1908;62:71-4.

11. Knapp P. The surgical treatment of double elevator paralysis. Trans Am Ophthalmol Soc 1969;67:304-23.

12. Taylor RH, Kraft SP. Aplasia of the inferior rectus muscle. Ophthalmology 1997;104:415-8.
13. Munoz M. Congenital absence of the inferior rectus muscle. Am J Ophthalmol 1996;121:327-9.

14. Vesley L. Aplasia of the inferior rectus oculi. Ceskoslovenska Oftalmologie 1965;21:477-8.

15. von Noorden GK, Hansell R. Clinical characteristics and treatment of isolated inferior rectus paralysis. Ophthalmology 1991;98:253-7.

Mohammed A. Majid ${ }^{1}$

Frank G. Ah-Fat ${ }^{2}$

Robert Wilson ${ }^{2}$

Ian B. Marsh ${ }^{2}$

${ }^{1}$ Department of Ophthalmology

Bristol Eye Hospital

Bristol BS1 2LX, UK

${ }^{2}$ Department of Ophthalmology

Walton Hospital

Liverpool L9 1AE, UK

Mr Mohammed A. Majid, FRCOphth

Department of Ophthalmology

Bristol Eye Hospital

Lower Maudlin Street

Bristol BS1 2LX, UK

Tel: $+44(0) 1179284853$

Fax: $+44(0) 1179251421$

e-mail: m.a.majid@cableinet.net

Sir,

Optical coherence tomography and multifocal electroretinography of $\mathrm{X}$-linked juvenile retinoschisis $\mathrm{X}$-linked retinoschisis (XLR) is a relatively rare bilateral vitreoretinal dystrophy which arises from mutations in the XLRS1 gene ${ }^{1}$ and results in visual loss in young men. We report the case of a 35-year-old man who presented with XLR and underwent functional and anatomical imaging using conventional techniques as well as multifocal electroretinography (mfERG) and optical coherence tomography (OCT).

\section{Case report}

A 35-year-old man was diagnosed as having retinoschisis 20 years ago. One of his two brothers, a maternal uncle and his maternal grandfather have also been diagnosed with this condition. He had a visual acuity of $6 / 60$ in the right eye and $6 / 36$ in the left eye.

Functional information was obtained from conventional electroretinography and from mfERG using a custom-built system with a 61 hexagonal display digitally back-projected onto a polysilicon screen. ${ }^{2}$ Anatomical images were obtained from fundus photography and optical coherence tomography.

Fundus photography revealed the typical stellate spoke-like pattern characteristic of this condition. Both eyes were affected; however, a larger area of affected macula was observed in the left eye.

OCT revealed splitting of the inner retinal layers in the macular areas of both eyes. This splitting was most marked in the region of the fovea (Fig. 1A, C). In other areas which appeared healthy on fundus photography, OCT revealed the presence of microcysts (Fig. 1B). A larger area of the left eye showed signs of damage. Condon et al. ${ }^{3}$ observed occasional bridges of retinal 